\title{
Rapid paracellular transmigration of Campylobacter jejuni across polarized epithelial cells without affecting TER: role of proteolytic-active HtrA cleaving E-cadherin but not fibronectin
}

Manja Boehm ${ }^{1 \dagger}$, Benjamin $\mathrm{Hoy}^{2 \dagger}{ }^{+}$, Manfred Rohde ${ }^{3 \dagger}$, Nicole Tegtmeyer ${ }^{1}$, Kristoffer T Bæk ${ }^{4}$, Omar A Oyarzabal ${ }^{5}$, Lone Brøndsted ${ }^{4}$, Silja Wessler ${ }^{2}$ and Steffen Backert ${ }^{1,6^{*}}$

\begin{abstract}
Background: Campylobacter jejuni is one of the most important bacterial pathogens causing food-borne illness worldwide. Crossing the intestinal epithelial barrier and host cell entry by C. jejuni is considered the primary reason of damage to the intestinal tissue, but the molecular mechanisms as well as major bacterial and host cell factors involved in this process are still widely unclear.

Results: In the present study, we characterized the serine protease HtrA (high-temperature requirement A) of C. jejuni as a secreted virulence factor with important proteolytic functions. Infection studies and in vitro cleavage assays showed that C. jejuni's HtrA triggers shedding of the extracellular E-cadherin NTF domain (90 kDa) of non-polarised INT-407 and polarized MKN-28 epithelial cells, but fibronectin was not cleaved as seen for H. pylori's HtrA. Deletion of the htrA gene in C. jejuni or expression of a protease-deficient S197A point mutant did not lead to loss of flagella or reduced bacterial motility, but led to severe defects in E-cadherin cleavage and transmigration of the bacteria across polarized MKN-28 cell layers. Unlike other highly invasive pathogens, transmigration across polarized cells by wild-type C. jejuni is highly efficient and is achieved within a few minutes of infection. Interestingly, E-cadherin cleavage by C. jejuni occurs in a limited fashion and transmigration required the intact flagella as well as HtrA protease activity, but does not reduce transepithelial electrical resistance (TER) as seen with Salmonella, Shigella, Listeria or Neisseria.
\end{abstract}

Conclusion: These results suggest that HtrA-mediated E-cadherin cleavage is involved in rapid crossing of the epithelial barrier by C. jejuni via a very specific mechanism using the paracellular route to reach basolateral surfaces, but does not cleave the fibronectin receptor which is necessary for cell entry.

Keywords: HtrA, E-cadherin, Fibronectin, MKN-28, Molecular pathogenesis, Cellular invasion, Signaling, TER, Virulence

\footnotetext{
* Correspondence: Steffen.Backert@ucd.ie

${ }^{\dagger}$ Equal contributors

${ }^{1}$ From the School for Medicine and Medical Science, University College Dublin, Belfield Campus, Dublin-4, Ireland

${ }^{6}$ University College Dublin, UCD School of Biomolecular and Biomedical

Sciences, Science Center West L231, Belfield Campus, Dublin 4, Ireland

Full list of author information is available at the end of the article
} 


\section{Introduction}

Infections with pathogenic food-borne bacteria constitute one of the leading causes of morbidity and mortality in humans. The World Health Organization (WHO) suggests that the human population worldwide suffers from about 4.5 billion incidences of gastroenteritis annually, causing approximately 1.8 million deaths [1]. Various Campylobacter species have been identified as the leading enteric bacterial infection worldwide [2,3]. Campylobacter jejuni is considered as a classical zoonotic pathogen, as it is found in the normal intestinal flora in many birds and mammals. Since C. jejuni colonizes various food animals, it can contaminate food products during processing [4]. After ingestion by a human host, these bacteria use their flagella-driven motility to colonize the epithelial cells of the ileum and colon. Here, they can interfere with normal functions in the intestinal tract, leading to diseases associated with fever, malaise, abdominal pain and watery diarrhoea [2,3]. In addition, a minority of infected individuals may develop late complications such as Reiter's reactive arthritis or GuillainBarrè and Miller-Fisher syndromes [5]. There is increasing evidence showing that $C$. jejuni disturbs the normal absorptive capacity of the human intestine by damaging epithelial cell functions, either by cell invasion, the production of pathogenicity-associated factors or indirectly by triggering inflammatory responses [3,6-8].

It has been proposed that transmigration across and invasion into intestinal epithelial cells during infection is a major reason of $C$. jejuni-triggered tissue damage [2-4]. Investigation of gut biopsies obtained from infected patients and in vitro infection experiments of intestinal epithelial cells indicated that C. jejuni can enter human host cells [9-11]. Campylobacter jejuni expresses various adhesins in the outer-membrane including CadF, FlpA, JlpA and PEB1 [12-15]. For example, in vitro CadF is a well-known bacterial factor that binds to fibronectin, an important extracellular matrix $(\mathrm{ECM})$ protein and bridging factor to integrin receptors $[13,16,17]$. Maximal bacterial adherence and invasion of INT-407 intestinal epithelial cells is dependent on CadF and is associated with tyrosine phosphorylation of paxillin, a focal adhesion-based scaffolding factor [18]. The expression of $\mathrm{CadF}$ also seems to be required for the stimulation of the small Rho GTPases Rac1 and Cdc42 via fibronectin and integrin member $\beta 1$, that are required for $C$. jejuni host cell entry. The signalling pathways involved in the latter process have been described in detail [19-21]. However, fibronectin and integrin $\beta 1$ are basolateral receptor molecules and not commonly exposed at apical surfaces in the intestine. It is therefore unclear how $C$. jejuni gains access to these receptors during infection.

To access deeper tissues and cause short- or long-term infections in the human body, various pathogenic bacteria, including Salmonella, Shigella, Listeria or Neisseria, must overcome the epithelial barrier [22,23]. These important bacterial pathogens are able to cross polarised intestinal epithelial cells by different mechanisms, known as the paracellular and the transcellular routes. Bacteria using the transcellular route enter host cells at apical surfaces followed by intracellular trafficking and leave these cells at the basolateral surface. In contrast, bacteria specialised on the paracellular route cross the epithelial barrier by passage between neighbouring epithelial cells and overcome the tight junctions and adherens junctions [24]. In the case of C. jejuni, the literature is highly controversial. While some groups reported the paracellular route, others described the transcellular model or a mix of both [25-30]. In general, the host factors and bacterial factors involved in the transmigration process of C. jejuni are still unclear [31].

We have recently shown that a closely related pathogen, Helicobacter pylori, secretes a novel bacterial virulence determinant into the culture supernatant, the serine protease HtrA [32-34], which is also present in C. jejuni [35-37]. HtrA proteins constitute a group of heat shock induced serine proteases that influence the adhesion and invasion properties of different bacterial pathogens. HtrA proteins typically consist of a signal peptide, a trypsin-like serine protease domain and one or two protein interaction (PDZ) domains. In addition, by binding of the PDZ domain in one HtrA molecule to that in other HtrA molecules, HtrA can build-up to highly proteolytic active oligomers that also function as a chaperone [38]. The HtrA protease domain consists of an active site, called the catalytic triad, which is formed by the conserved amino acid residues histidine, aspartatic acid and serine [39]. Many bacterial HtrA proteins are suggested to be localized in the periplasm and to be involved in quality control of envelope proteins by degradation of misfolded proteins as well as prevention of formation of aggregates [40]. Thus, it was surprising to find that HtrA exhibits the capability of extracelluar transport in $H$. pylori $[34,41]$, where it could cleave host surface molecules. We identified that $H$. pylori $\mathrm{HtrA}$ directly cleaves the junctional protein and tumor suppressor E-cadherin and fibronectin on the surface of gastric epithelial host cells. HtrA-mediated cleavage of E-cadherin facilitated the loss of the adherence junction complex leading to the disruption of the epithelial barrier function in response to $H$. pylori infection [32] and may also apply to $C$. jejuni HtrA [33]. Here, we present the results from a detailed investigation to determine if $C$. jejuni HtrA can cleave both E-cadherin and fibronectin, and whether HtrA protease activity is required for transmigration across polarised epithelial cells. Our findings show that $C$. jejuni can effectively cross polarised epithelial cells in an HtrA-protease dependent fashion without affecting TER.

\section{Results \& discussion}

HtrA protease is conserved in $H$. pylori and C. jejuni

Recently, HtrA of the gastric pathogen $H$. pylori was reported to be specifically secreted into the cell culture 
supernatant, where it can cleave the ectodomain of the host cell adhesion protein and tumour-suppressor E-cadherin, and degrades fibronectin [32]. A sequence alignment of HtrAs from different $C$. jejuni and $H$. pylori strains was performed and revealed a high degree of similarity between the HtrA domains and protein sequences (Additional file 1: Figure S1A). We also found that the amino acids in the catalytic triad (histidine, aspartate and serine) are conserved and at the expected position among these proteins (Additional file 1: Figure S1B, shaded with yellow). These results suggest that HtrA's are highly conserved in various $C$. jejuni isolates. We therefore suspected that $C$. jejuni may also use its HtrA protease to cross the barrier of polarised epithelial cells.

\section{Analysis of wild-type and $h$ trA mutant $C$. jejuni by electron microscopy and motility assays}

We first aimed to investigate several $h t r A$ mutants in $C$. jejuni, including the wild-type (wt) strains 81-176 and NCTC11168, their isogenic $\Delta h t r A$ deletion mutants and NCTC11168 htrA S197A, a strain with complemented htrA carrying a point mutation at S197A in the active centre, rendering the protein catalytically inactive [36]. The morphology of the produced $C$. jejuni strains was analysed by scanning electron microscopy (FESEM). Comparison of the C. jejuni wt strains 81-176 and NCTC11168 with their corresponding htrA mutants revealed some slight differences at the bacterial surface, but no major phenoptypical alterations were noted (Figure 1). In addition, all htrA mutants produced intact bipolar flagella as compared to their wt counterparts (Figure 1, blue arrows). Studies of all strains by another electron microscopic method (negative staining) revealed similar results and thus confirmed our findings (Additional file 1: Figure S2). Motility assays revealed that both $C$. jejuni wt and $h t r A$ mutant strains were highly motile, suggesting that mutation of $h t r A$ does not significantly affect this important pathogenicity property of the bacteria (Figure 2).

\section{HtrA's of strains $81-176$ and NCTC11168 form active multimers}

We tested the assumption that $C$. jejuni wt strains 81-176 and NCTC11168 can generate proteolytic active HtrA multimers. For this purpose, the wt strains and corresponding isogenic $\Delta h t r A$ deletion and S197A mutants were grown in BHI broth medium, followed by casein zymography of total cell lysates [32]. The results show that the HtrA protein was not synthesized by the $\Delta h t r A$ mutants, whereas HtrA is produced by the wt and S197A isolates, and only wt C. jejuni formed caseinolytic active multimers as expected (Figure 3A). These observations are in agreement with reports on HtrA in other bacteria such as E. coli where the HtrA multimers are highly proteolytic active rather than the monomer [38]. The identity of $C$. jejuni HtrA monomers and multimers was approved by mass spectrometry of the excised bands as described [33]. The presence or absence of HtrA expression
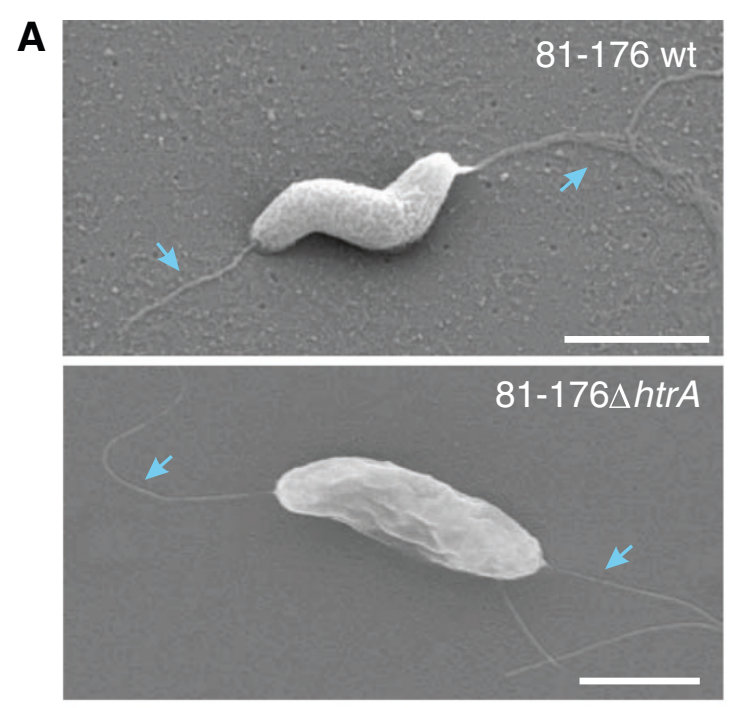

B
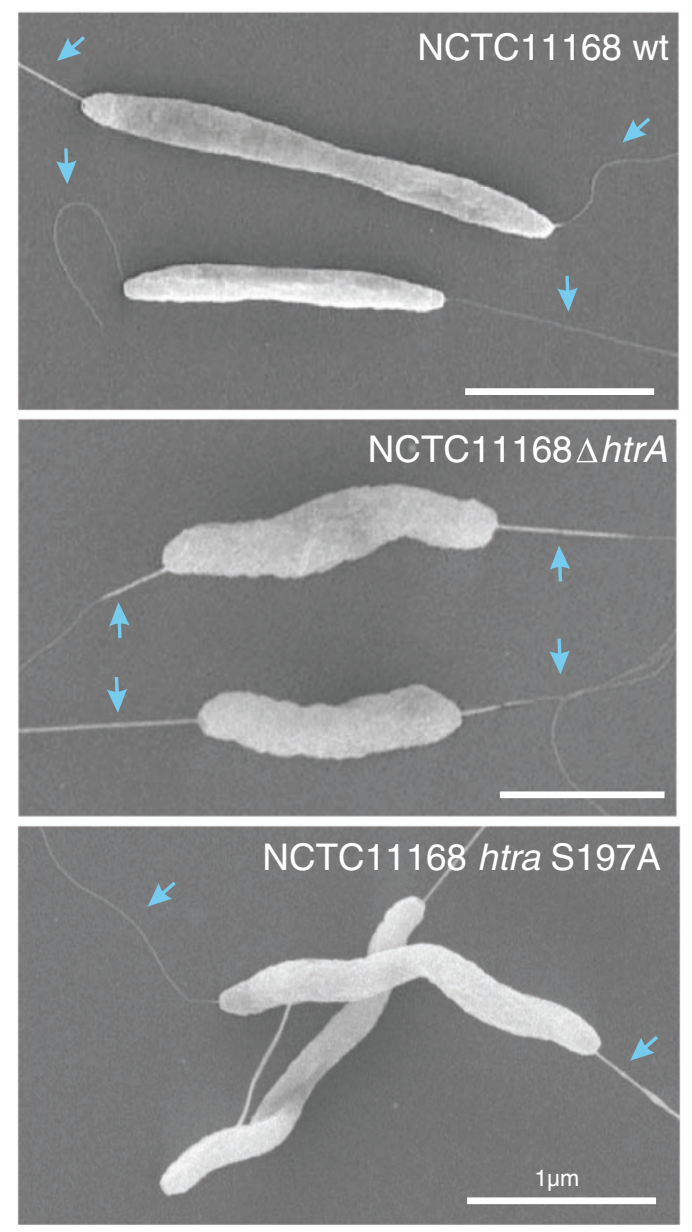

Figure 1 Analysis of $C$. jejuni and $h$ trA mutants by scanning electron microscopy and motility assays. Scanning electron microscopy revealed that wild-type (wt) C. jejuni and different $h$ trA mutants of strain 81-176 (A) and NCTC11168 (B) produce intact bipolar flagella (blue arrows) and only slight morphological differences. Each bar corresponds to $1 \mu \mathrm{m}$. 
A

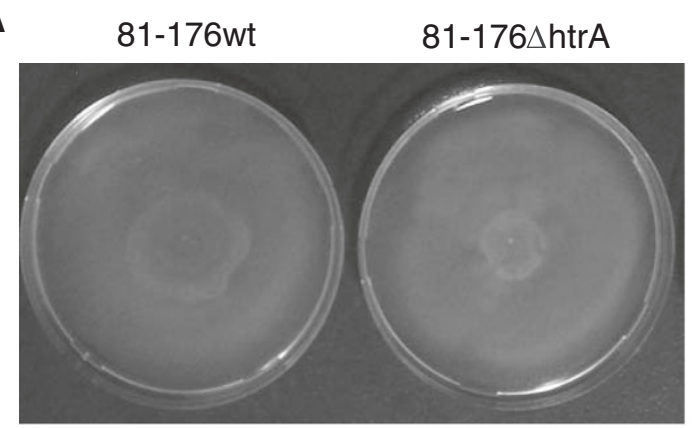

C

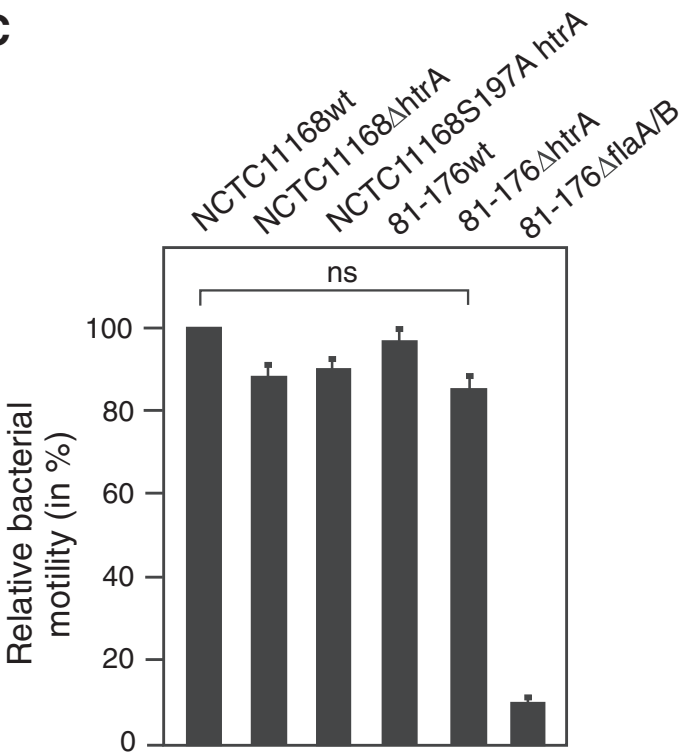

B

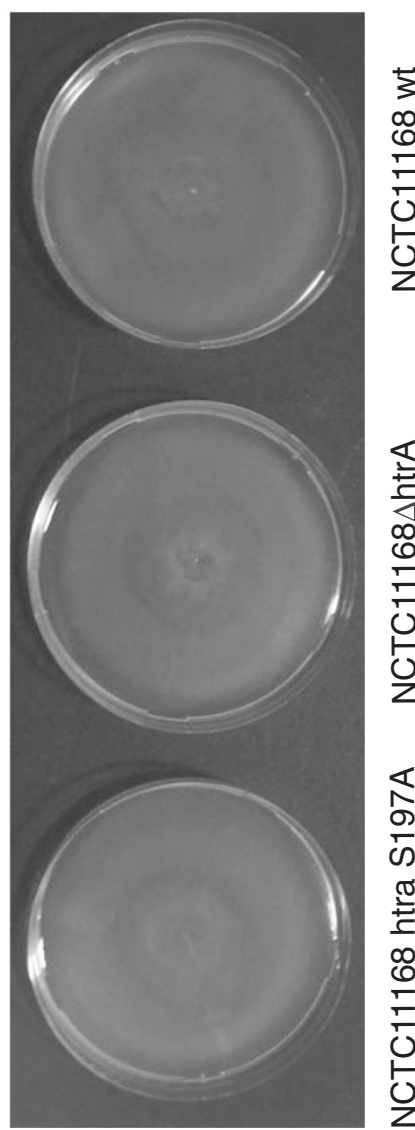

Figure 2 Different $C$. jejuni wild-type and htrA mutant strains exhibit high motility. Motility assays were performed for $36 \mathrm{~h}$ on agar using wild-type (wt) C. jejuni and different htrA mutants of strain 81-176 (A) and NCTC11168 (B) and revealed high motility for each strain. (C) Quantification of motility using the indicated wt and mutant $C$. jejuni strains. One hundred percent of motility corresponds to the highest swarming capability presented by C. jejuni wt strain NCTC11168. No significant (ns) differences were seen among the various highly motile strains. The $\triangle$ flaAvB mutant was used motility-deficient a control.

was further confirmed by anti-HtrA Western blotting using an anti-CadF blot as loading control (Figure 3A, bottom).

\section{Multiple C. jejuni wt strains express active HtrA multimers}

To exclude the possibility that HtrA activity is restricted to the above $C$. jejuni isolates, we tested a larger collection of wt strains for their expression of active HtrA proteins. Total cell lysates from C. jejuni wt RM1221, ATCC43430, TGH9011, 1849, 1543/01, 2703/01 and ST3046 were prepared and analyzed for HtrA protease activities by casein zymography. All tested strains expressed the active HtrA multimer with a molecular size of $\sim 200 \mathrm{kDa}$, albeit at various extent, while only faint bands of the monomer at $\sim 53 \mathrm{kDa}$ were seen (Figure 3B). We could also confirm previous findings that these native $C$. jejuni HtrA's were very similar to recombinant $H$. pylori HtrA forming highly active multimers at the same size $\sim 200 \mathrm{kDa}$ [33] (Figure 3B, lane 1).

\section{C. jejuni secretes HtrA into the culture supernatant where they form active multimers}

The remarkable sequence homology between HtrA's from $H$. pylori and $C$. jejuni led us to propose that active $C$. jejuni HtrA maybe also secreted into the cell culture supernatant by various strains, similar to its $H$. pylori counterpart. To test this hypothesis, $C$. jejuni wt strains 81-176 and NCTC11168 and its isogenic $\Delta$ htrA deletion mutants were grown in BHI broth medium and bacteria-free supernatants were prepared, followed by casein zymography. The results show that the HtrA proteins from wt $C$. jejuni were found in the bacterial culture supernatant fraction where they also form caseinolytic active multimers (Figure 4A and data not shown).

\section{In vitro cleavage properties of purified HtrA's of $C$. jejuni} and $H$. pylori

H. pylori HtrA has recently been shown to cleave the cell adhesion protein E-cadherin and the extracellular matrix 
A

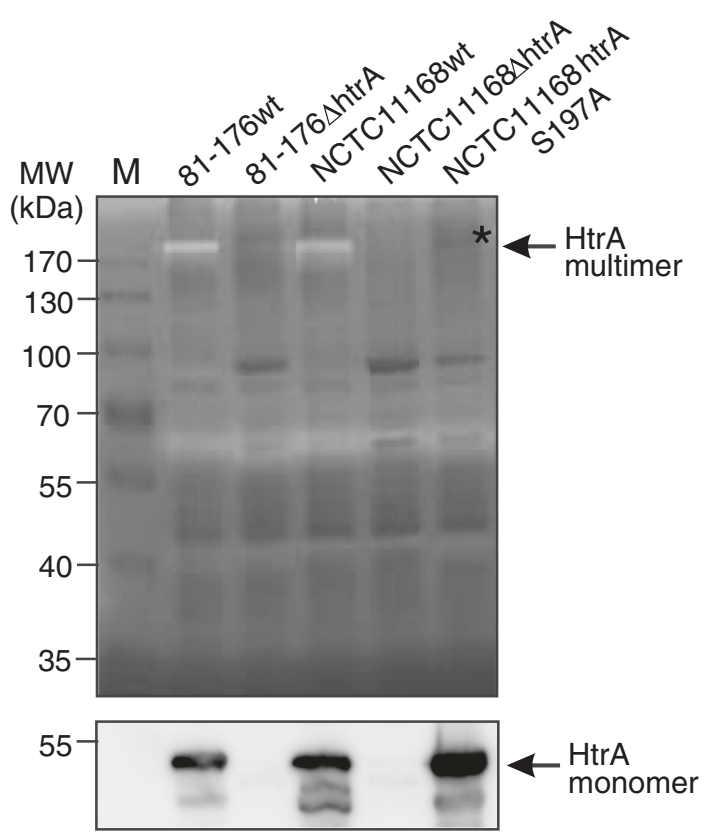

$\alpha-\mathrm{HtrA}$

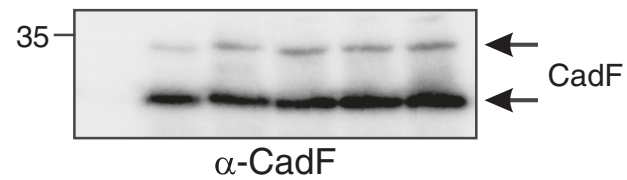

B

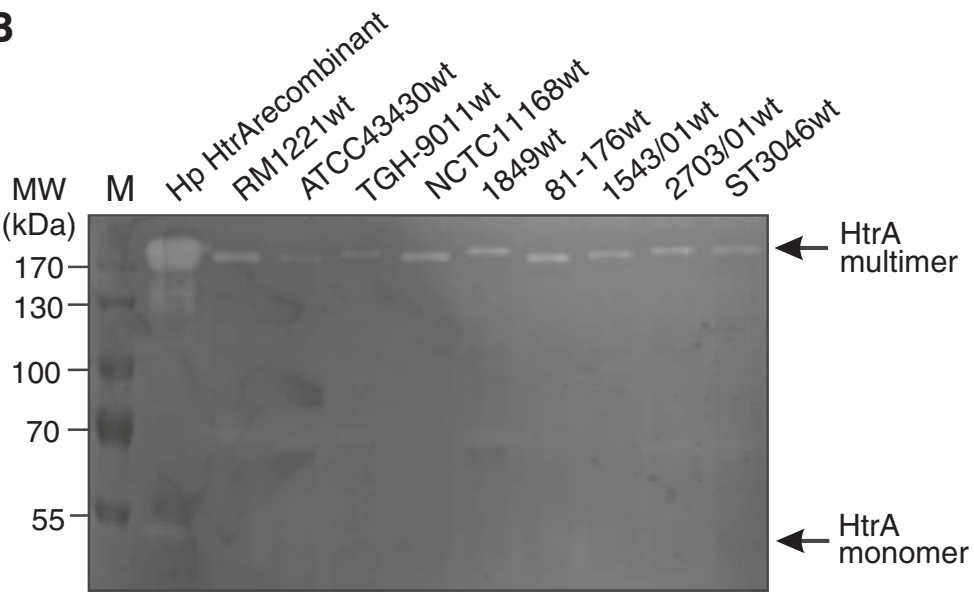

Figure 3 Detection of proteolytic active HtrA multimers in different C. jejuni wild-type and mutant strains. (A) Total cell lysates of plate-grown

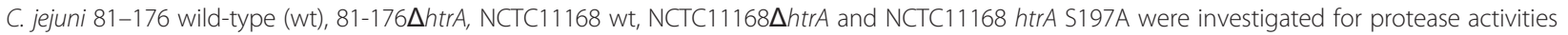
by casein zymography. The position of active monomeric and multimeric HtrA proteins is indicated with arrows. Active monomeric HtrA was only weakly visible as indicated. The asterisk indicates the inactive HtrA multimer formed by the S197A point mutant. (B) Total cell lysates of the indicated plate-grown wt strains were separated on non-denaturing gels. Proteolytic active HtrA bands were detected by casein zymography as described. Purified recombinant $H$. pylori (Hp) HtrA served as control.

protein fibronectin [32]. Full length E-cadherin has a molecular weight of about $130 \mathrm{kDa}$ and is composed of a $\sim 90 \mathrm{kDa}$ extracellular domain amino-terminal fragment (NTF) and a $\sim 40 \mathrm{kDa}$ carboxy-terminal fragment (CTF1) [32]. To determine whether C. jejuni HtrA can cleave Ecadherin into specific subfragments recombinant HtrAs was purified. As expected, $C$. jejuni HtrA had slightly different molecular weight as compared to its $H$. pylori counterpart, due to the smaller size of the expressed protein (472 vs. 476 amino acids) (Additional file 1: Figure S3). Recombinant $C$. jejuni $\mathrm{HtrA}$ was then incubated with recombinant full-length E-cadherin. The ectodomain shedding 
A

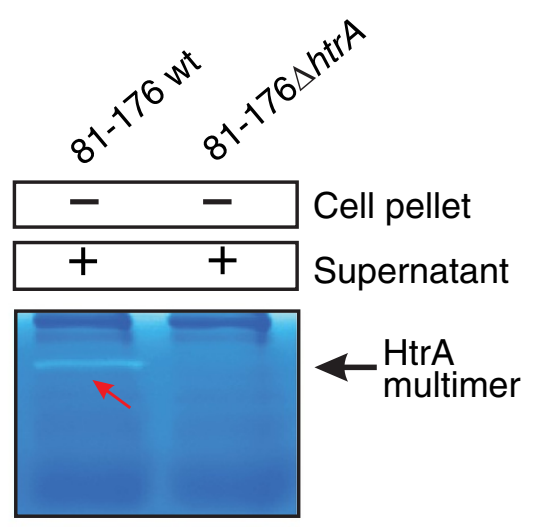

B

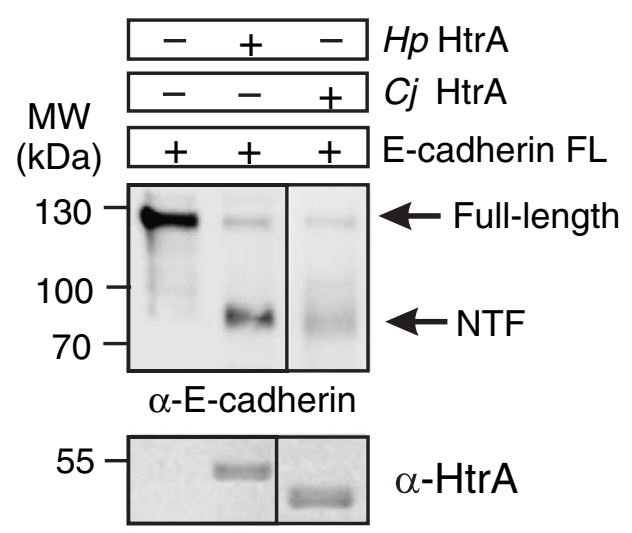

C

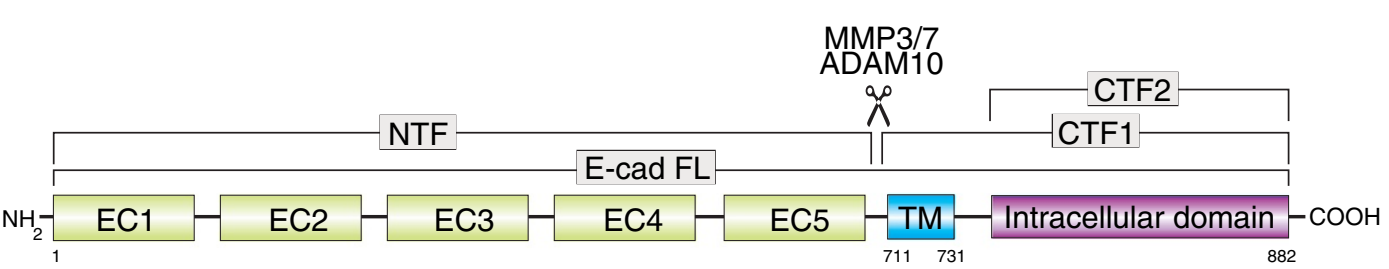
$\mathrm{NH}_{2}-\mathrm{EC} 1-\mathrm{EC} 2-\mathrm{EC} 3-\mathrm{EC} 4-\mathrm{EC} 5-\mathrm{His}-\mathrm{COOH}$

D

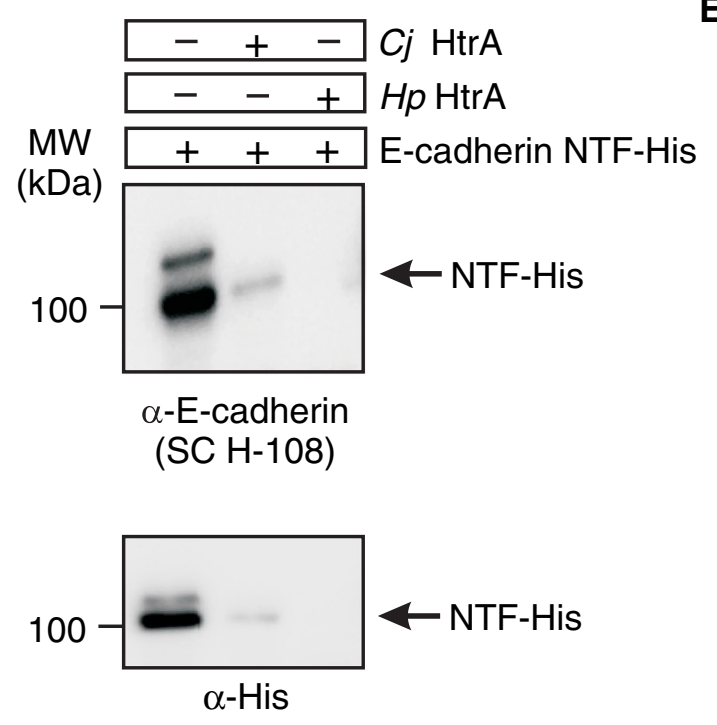

$\mathbf{E}$

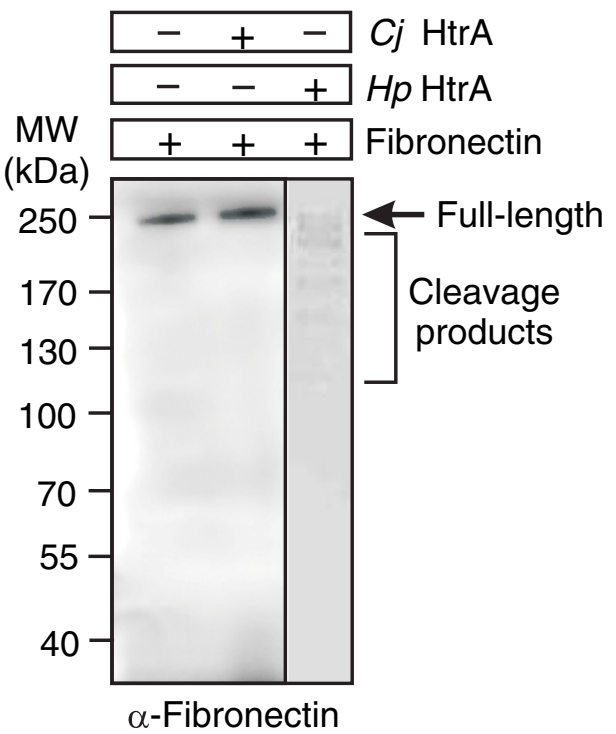

Figure $4 \mathrm{C}$. jejuni $\mathrm{HtrA}$ is secreted into the supernatant, forms proteolytic active multimers and recombinant $C$. jejuni HtrA cleaves E-cadherin but not fibronectin. (A) Filtered supernatants of broth-grown wild-type (wt) or htrA mutant C. jejuni (Cj) were subjected to zymography to detect proteolytic active HtrA multimers. (B) In vitro cleavage of full-length (FL) E-cadherin incubated with purified Cj HtrA or $\mathrm{H}$. pylori $(\mathrm{Hp}) \mathrm{HtrA}$ results in shedding of the extracellular N-terminal fragment (NTF). The anti-HtrA blot serves as loading control. (C) Schematic presentation of the domain structure of full-length human E-cadherin (GenBank accession number CAA78353.1) and the His-tagged NTF domain used for cleavage assays. E-cadherin consists of five extracellular domains (EC1-EC5) comprising the NTF domain, a transmembrane (TM) domain and an intracellular domain called C-terminal fragment (CTF). The cleavage site by some host cell proteases is indicated. (D) In vitro cleavage of the recombinant E-cadherin NTF domain incubated with purified Cj HtrA or Hp HtrA results in cleavage and disappearance of the $90 \mathrm{kDa}$ NTF fragment. (E) In vitro cleavage assay of fibronectin incubated with purified HtrAs under identical conditions shows that fibronectin can be cleaved by $\mathrm{Hp} \mathrm{HtrA} \mathrm{but} \mathrm{not} \mathrm{Cj} \mathrm{HtrA}$. All reactions were incubated for $16 \mathrm{~h}$ at $37^{\circ} \mathrm{C}$. 
of E-cadherin was detected using $\alpha$-E-cadherin antibodies recognising the EC5 subunit in the NTF domain. Like its H. pylori counterpart, it was shown that C. jejuni HtrA cleaved E-cadherin as monitored by the disappearance of full-length protein band and increasing amounts of the $\sim 90 \mathrm{kDa}$ NTF domain (Figure 4B/C). In addition, we performed assays with the purified recombinant NTF domain (amino acids 1-707 followed by a His-tag) showing that this domain disappears upon HtrA cleavage as shown by anti-E-cadherin and anti-His blots, indicating that the cleavage site of HtrA is indeed in the extracellular part of E-cadherin adjacent to the transmembrane domain (amino acids 711-731) (Figure 4C/D). Interestingly, E-cadherin ectodomain cleavage by $C$. jejuni HtrA was not as efficient as compared to $H$. pylori $\mathrm{HtrA}$, but band sizes were similar, albeit with different intensity. Moreover, $H$. pylori HtrA cleaved purified fibronectin into multiple subfragments, while C. jejuni HtrA did not cleave fibronectin at all (Figure 4E). These observations suggest that although HtrA from $H$. pylori and C. jejuni share substantial

A

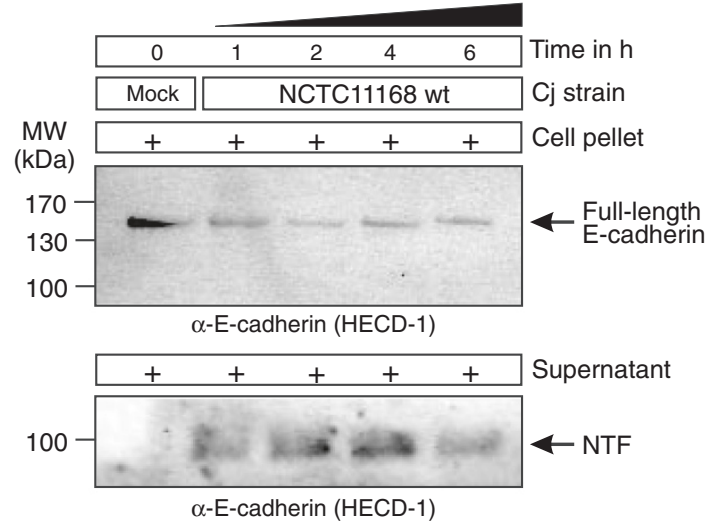

B

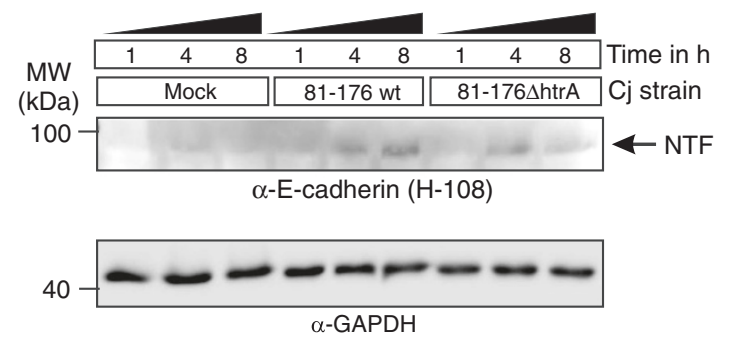

Figure 5 In vivo cleavage of E-cadherin during C. jejuni infection of non-polarised INT-407 cells and polarised MKN-28 cells. (A) INT-407 cells were infected with C. jejuni NCTC11168 wild-type (wt) strain in a time course. The Western blot shows changes of cell-associated full-length E-cadherin and reveals the generation of $90 \mathrm{kDa}$ NTF domain in the supernatant over time. (B) Polarised MKN-28 cells were infected with C. jejuni 81-176 wt and htrA mutant strains in a time course. Supernatants were harvested at each time point, and the E-cadherin NTF fragment was detected using the indicated antibody. GAPDH expression levels were determined as loading control of total cellular protein.
A \begin{tabular}{|llllllll|}
\hline 1 & 3 & 5 & 7 & 9 & 11 & 13 & 14 \\
\hline
\end{tabular}

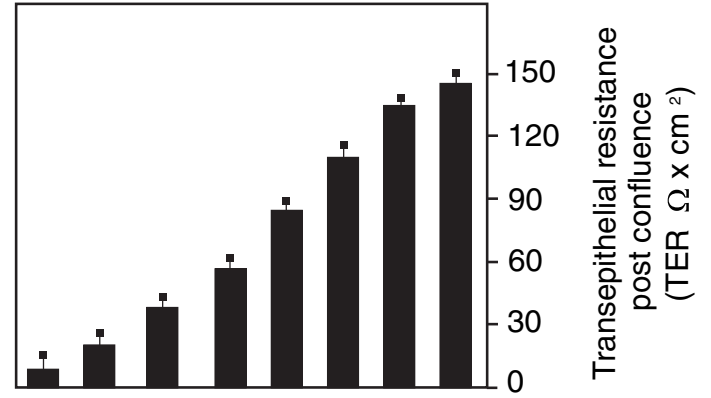

B

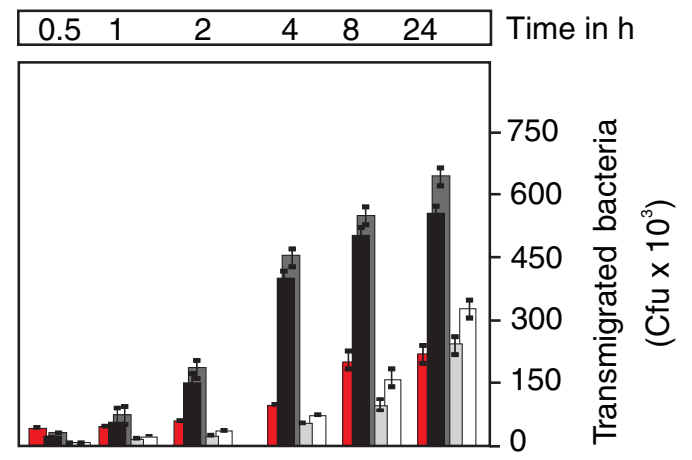

C
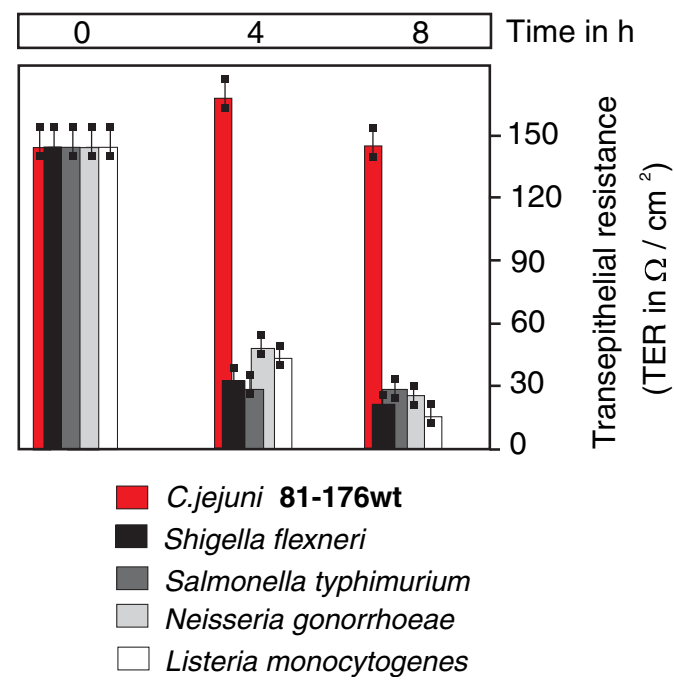

Figure 6 Transmigration characteristics of different bacterial pathogens across polarised MKN-28 cells using a transwell filter system. (A) MKN-28 cells were grown to reach monolayers in a transwell filter system. The cells were then differentiated and TER was allowed to establish over 14 days as indicated. (B) MKN-28 cells were then infected and CFUs of transmigrated C. jejuni wt strain 81-176 and some other indicated bacterial pathogens in a time course. Transmigrated bacteria were harvested from the bottom chambers, grown on MH plates, and CFUs were determined in triplicates. (C) TER measurement of infected MKN-28 cells during the indicated time course. 
sequence homology, significant differences exist for certain host substrates. The above experiments were all performed at $37^{\circ} \mathrm{C}$, which is the body temperature of mammalian hosts. However, since C. jejuni also exhibits host specificity for avian species $\left(42^{\circ} \mathrm{C}\right)$, we tested if HtrA exhibits different cleavage properties at $42^{\circ} \mathrm{C}$. Interestingly, the cleavage patterns were identical between $37^{\circ} \mathrm{C}$ and $42^{\circ} \mathrm{C}$ (Figure 4C/D and Additional file 1: Figure S4).

In vivo cleavage of E-cadherin in C. jejuni infected INT-407 or MKN-28 cells

The next aim was to investigate if $C$. jejuni HtrA can cleave E-cadherin during infection in vivo. For this purpose, E-cadherin-expressing INT-407 and MKN-28 cells were infected with $C$. jejuni wt strains NCT11168 or 81-176 in a time course for the indicated periods of time (up to $8 \mathrm{~h}$ ) and the cleavage of E-cadherin was determined by immunoblotting. The results show that the overall amount of full-length E-cadherin dropped down during infection, but was not eliminated (Figure 5A). In addition, the signals of the entire $90 \mathrm{kDa}$ NTF increased over time up to 4 hours and then dropped somewhat, as detected in the supernatant of infected cells (Figure 5B). In contrast, significantly reduced E-cadherin ectodomain shedding was observed during infection with the isogenic $\triangle h t r A$ or S197A mutants (Figure 5 and data not shown). We also found that fibronectin is not cleaved during $C$. jejuni infection (not shown), which is in agreement with the earlier findings that fibronectin is a major host cell factor necessary for $C$. jejuni binding and invasion $[13,16,17]$.

\section{Wild-type $C$. jejuni transmigrate efficiently across} polarised MKN-28 monolayers but do not reduce TER Is HtrA activity important for transmigration of $C$. jejuni across polarised epithelial cells? To answer this question, MKN-28 cells were seeded and differentiated in a transwellfilter system. The transepithelial electrical resistance (TER) was followed over time and TER values between 140-150 $\Omega / \mathrm{cm}^{2}$ were achieved 14 days after reaching confluence (Figure 6A), similarly to previously reported data [42]. Proper cell monolayers and junction formation were confirmed by E-cadherin and JAM staining in immunofluorescence microscopy [32]. MKN-28 cells were then infected with $C$. jejuni and other invasive pathogens as controls, including Salmonella typhimurium, Shigella flexneri, Neisseria gonorrhoeae and Listeria monocytogenes for 0.5 to $24 \mathrm{~h}$, followed by determination of the colony forming units (CFU) in the lower chambers. The results show that $C$. jejuni transmigrated quickly, even much faster than the other pathogens during the first $30 \mathrm{~min}$ and increased up to 200,000 CFU over time (Figure 6B). At different time points between 2$24 \mathrm{~h}$, the transmigration rates of $C$. jejuni were similar to that of $N$. gonorrhoeae and L. monocytogenes, but about 3 times lower than S. typhimurium or S. flexneri (Figure 6B).

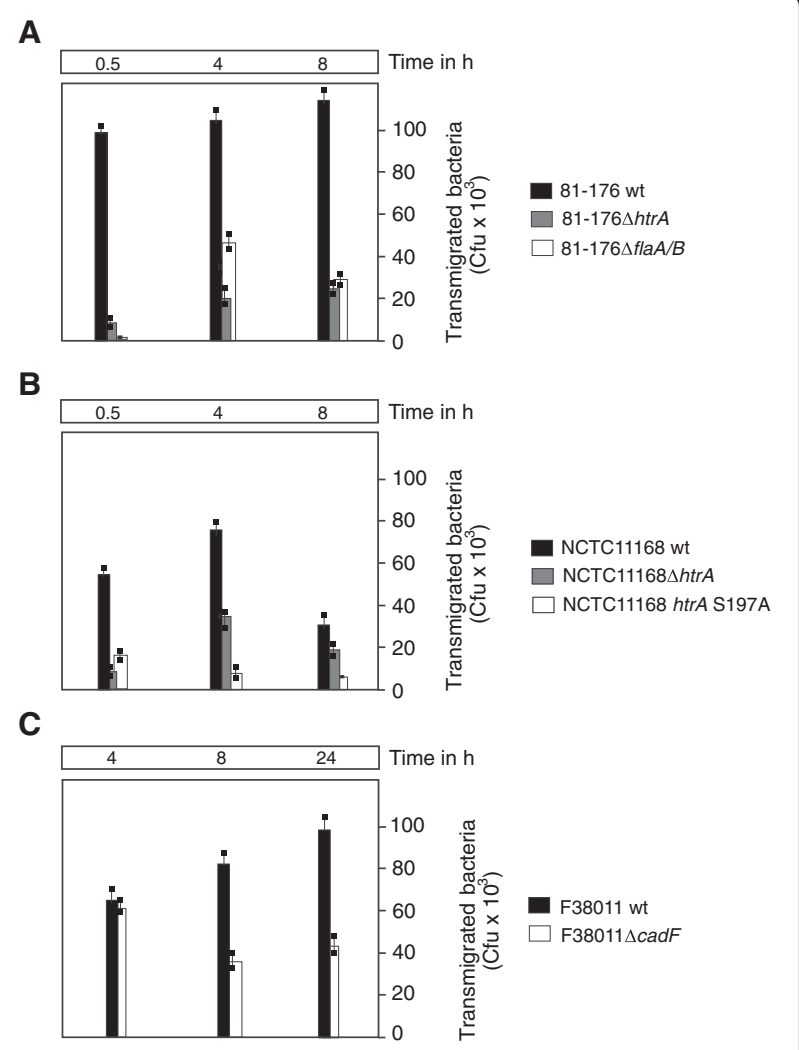

Figure 7 Role of HtrA in transmigration of $C$. jejuni across polarised MKN-28 cells. (A-C) Differentiated MKN-28 epithelial cells were grown in a transwell filter system for 14 days, and then infected with the indicated wild-type (wt) and mutant C. jejuni strains in the indicated time course. Transmigrated bacteria were harvested from the bottom chambers, grown on MH plates, and CFUs were determined in triplicates.

We also noted that S. typhimurium or S. flexneri multiply quickly in culture medium as compared to the other bacteria that did not, which can explain these higher CFUs at time points $>24 \mathrm{~h}$. Non-pathogenic E. coli Top10 did not transmigrate under the same conditions as expected (data not shown). Interestingly, the measurement of TER during infection revealed that while $S$. typhimurium, S. flexneri, N. gonorrhoeae and L. monocytogenes reduced TER substantially over time, infection with $C$. jejuni did not influence TER significantly (Figure 6C). This indicates that $C$. jejuni, in contrast to the other pathogens, does not decrease TER. Thus, $C$. jejuni does not induce a permanent opening of the cell-tocell junctions in order to induce its transmigration.

\section{C. jejuni $\Delta$ htrA and S197A point mutants have a strong defect in transmigration}

To finally investigate if the expression of HtrA is important for triggering transmigration of the bacteria across a polarised epithelium, MKN-28 cells were grown and differentiated as described above, followed by infection with C. jejuni wt strains 81-176 or NCTC11168 and their 
isogenic $\Delta h t r A$ deletion mutants. It could be shown that both $\triangle h t r A$ mutants exhibited a strong defect in transmigration as compared to wt $C$. jejuni (Figure 7A/B). In addition, $C$. jejuni expressing the protease-inactive S197A point mutant and a flagellar mutant $(\triangle f l a A / B)$ were also widely deficient in transmigration, while a $\Delta c a d F$ mutant showed similar transmigration rates at the $4 \mathrm{~h}$ time point (Figure $7 \mathrm{~B} / \mathrm{C}$ ). These observations suggest that secreted HtrA of C. jejuni and its protease activity, but also the flagellar-driven motility play crucial roles in crossing the epithelial barrier by this pathogen.

\section{Conclusions}

The intestinal mucosa in the human intestine forms a tight barrier, which protects against host invasion by commensals, non-pathogenic microbes residing in the intestinal lumen. Some enteric pathogenic bacteria, such as Salmonella, Shigella, or Listeria, have specific tissue-invading properties and can physically breach the intestinal mucosal barrier [43-45]. In general, these bacterial pathogens can translocate via a paracellular route or a transcellular route. A well studied example is Salmonella enterica serovar Typhimurium which can cross the intestinal barrier preferentially by entering $M$ cells, although they can also enter and pass through epithelial cells of the intestinal tract in vivo and in cultured polarized epithelial cells in vitro [46-48]. However, very little is known about $C$. jejuni transmigration. Previous work has revealed that $C$. jejuni can translocate across Caco-2 and other polarized cell monolayers without a concomitant loss in TER [25,49-51], indicating that $C$. jejuni can cross a given polarised cell monolayer whose integrity, however, remains intact. In contrast, other research groups reported on a time-dependent decrease of TER caused by $C$. jejuni infection, while the bacterial factor(s) triggering a reduction in TER were not addressed [52-54]. Thus, there are some conflicting data in the literature and a consensus is yet to be reached among investigators as to the mechanism of translocation.

Our previous data suggested that HtrA chaperone activity plays a major role in C. jejuni host cell binding, whereas HtrA protease activity mainly affected invasion [36]. Novel data presented in this work show that HtrA from C. jejuni can be secreted into the cell culture supernatant during bacterial growth or during infection. In addition, it was shown that $C$. jejuni can cross polarised epithelial monolayers very rapidly. The first viable transmigrated wt $C$. jejuni CFU were detected after 15-30 min (Figure 6 and data not shown). In contrast, C. jejuni invasion of different host cell types was commonly observed at much later time points and was obvious between 4-6 hours or later during infection [18-21,55,56]. These facts alone already indicate that transmigration of C. jejuni exclude the transcellular route as a major mechanism in MKN-28 cells, which would of course take much longer time until the first bacteria reach the basolateral compartment. Instead, our findings strongly argue for the paracellular route mainly used by $C$. jejuni 81-176 and NCTC11168. Moreover, it was found that deletion of $h t r A$ or complementation with a proteaseinactive S197A mutant exhibited a strongly reduced transmigration potential, indicating that HtrA's protease activity indeed plays a role in this process. In addition, all htr $A$ mutants described here expressed flagella and were highly motile. Thus, we describe here the first $C$. jejuni mutants with very high motility, but having very low transmigration and invasion potential, thus behaving like a classical avirulent $\triangle f l a A / B$ mutant.

In addition, evidence was presented that recombinant HtrA from C. jejuni can cleave-off in vitro and during infection in vivo the NTF domain from E-cadherin, a major adherens junctional protein, while it leaves the receptor molecule fibronectin uncleaved. Thus, cleavage of E-cadherin may be involved in $C$. jejuni transmigration. The exact cleavage site(s) in E-cadherin, however, are yet unknown and should be investigated in future studies. In addition, the total amount of cell-based E-cadherin dropped down during the course of infection, but did not lead to a complete cleavage, even at late time points of infection (8 hours). We therefore propose that cleavage of E-cadherin by HtrA during infection is a strictly controlled, temporary and locally restricted process, possibly achieved by surfaceexposed and/or secreted HtrA proteins when the bacteria enter the intercellular space. Host cells continuously translate large amounts of E-cadherin proteins, and therefore the host cell machinery could rapidly replace cleaved proteins. This hypothesis could also explain why no significant reduction in TER was observed during infection with $C$. jejuni, and suggests that these bacteria can close the "door" behind them, which appears as a clever novel infection mechanism during bacterial transmigration across polarised gut epithelial cells.

\section{Methods \\ Campylobacter strains}

The C. jejuni strains RM1221, ATCC43430, TGH-9011, NCTC11168, 1849, 81-176, 1543/01, 2703/01, ST3046 and F38011 were used in this study. The isogenic mutants

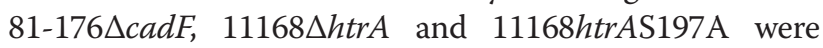
recently described [33,35-37]. The isogenic F38011 $\Delta c a d F$ and $81-176 \triangle f l a A / B$ mutants were kindly provided by Michael Konkel [57] and Patricia Guerry [58]. All C. jejuni strains were grown on Campylobacter blood-free selective Agar Base (Oxoid) containing Campylobacter growth supplement (Oxoid) or on Mueller-Hinton (MH) agar amended with $50 \mu \mathrm{g} / \mathrm{ml} \mathrm{kanamycin} \mathrm{or} 30 \mu \mathrm{g} / \mathrm{ml}$ or chloramphenicol at $37^{\circ} \mathrm{C}$ under microaerobic conditions (generated by CampyGen, Oxoid) for 48 hours. 


\section{Other bacterial species}

Salmonella typhimurium strain NCTC12023 was kindly provided by M. Hensel (University Osnabrueck/Germany). Neisseria gonorrhoeae strain 6B10 is a gift of T. Meyer (Max Planck Institute for Infection Biology Berlin/Germany). Shigella flexneri strain 15.4 is a clinical isolate from the Medical School Magdeburg/Germany, and Listeria monocytogenes strain EGD (Serotyp 1/2a) was kindly provided by J. Wehland (HZI Braunschweig/Germany). As control, we used the non-pathogenic Escherichia coli strain Top10 (Invitrogen). Each of these bacteria was grown overnight at $37^{\circ} \mathrm{C}$ on conventional LB agar plates.

\section{HtrA secretion assays}

C. jejuni wild-type and $\Delta h t r A$ deletion mutant strains were grown in BHI broth medium for 12 hours to an $\mathrm{OD}_{600 \mathrm{~nm}} \sim 1.0$. The supernatant and the cell pellets were separated by centrifugation at 4,000 rpm, and the supernatant was further purified from remaining bacterial cells by passage through a $0.21 \mu \mathrm{m}$ sterile filter. The resulting bacterial pellets and supernatants were analysed by immunoblot and casein zymography analyses. Absence of live bacteria in the supernatant was confirmed by incubation on agar plates showing no growth.

\section{Motility assays}

Motility phenotypes of strains were tested in $\mathrm{MH}$ media containing $0.4 \%$ agar. Bacterial cells were harvested from a $36 \mathrm{~h}$ culture on conventional agar plates and resuspended in PBS to obtain an optical density at $600 \mathrm{~nm}$ of 0.45 (approximately $1 \times 10^{9} \mathrm{CFU} / \mathrm{ml}$ ). Subsequently, $2 \mu \mathrm{l}$ of a bacterial suspension of $2 \times 10^{8} \mathrm{CFU} / \mathrm{ml}$ were stabbed into motility agar. Plates were incubated at $37^{\circ} \mathrm{C}$ under microaerophilic conditions for $36 \mathrm{~h}$, followed by measuring the diameter of the resulting swarms. The final data were the mean of at least five separate measurements from three experiments.

\section{Host cell lines}

Human embryonic intestinal epithelial cells (INT-407, non-polarised), obtained from the American Type Culture Collection (ATCC CCL-6) and polarised MKN-28 cells were grown in RPMI-1640 medium containing Lglutamine and Earle's salts (Gibco). After reaching about $70 \%$ confluency, the cells were washed two times with PBS, and then starved for $12 \mathrm{~h}$ before infection.

\section{Infection studies}

For the infection experiments, INT-407 cells were seeded to give $4 \times 10^{5} \mathrm{CFU}$ in 12 -well tissue culture plates. The culture medium was replaced with fresh medium without antibiotics $1 \mathrm{~h}$ before infection. Bacteria were suspended in culture medium, added to the cells at a multiplicity of infection (MOI) of 100, and co-incubated with host cells for the indicated periods of time per experiment.

\section{Transepithelial electrical resistance (TER) assay}

MKN-28 cells were cultured on $0.33 \mathrm{~cm}^{2}$ cell culture inserts with $3 \mu \mathrm{m}$ pore size (Millipore). The cells were allowed to form confluent monolayers, and then incubated for another 14 days. TER was measured with an Electrical Resistance System (ERS) (Millipore). Maximum resistance indicated that the cells reached maximal polarity. TER was calculated as Ohms $\mathrm{x} \mathrm{cm}^{2}$ by subtracting fluid resistance and multiplying by the monolayer surface area. Bacteria were suspended in culture medium, added to the cells at a multiplicity of infection (MOI) of 50, and co-incubated with host cells for the indicated periods of time per experiment. The number of CFU was determined by growth on $\mathrm{MH}$ or LB plates, respectively.

\section{HtrA expression, purification and E-cadherin cleavage in vitro}

Cloning of $H$. pylori htrA (HpHtrA aa18-aa475) and $C$. jejuni htrA (CjHtrA aa17-aa472) was described previously [33,34]. Briefly, the genes were amplified from genomic DNA excluding predicted signal peptides. PCR fragments flanked by restriction sites for $\mathrm{BamHI} / \mathrm{XmaI}$ were cloned into pGEX-6P-1 (GE Healthcare) to generate a GST-fusion protein. The expression and purification protocol was described in detail [34]. Cleavage assays of purified HtrA with recombinant human fulllength E-cadherin ( $\& \& D$ Systems), recombinant human His-tagged N-terminal NTF domain (Sino Biological) or human fibronectin (Calbiochem) were performed as described [32].

\section{SDS-PAGE and western blot}

Cells were lysed [32], proteins were separated by SDS-PAGE and tested for fibronectin (Santa Cruz) and E-cadherin using polyclonal antibodies recognizing the extracellular domain of E-cadherin (H-108 from Santa Cruz or HECD1 from BD Biosciences) and whole cell lysates were tested for GAPDH. The polyclonal anti-His tag antibody is from Qiagen and the rabbit HtrA antibody was described in [36,37]. Bacterial HtrAs were detected by Coomassie staining (BioRad).

\section{Casein zymography}

Bacterial lysates, culture supernatants or recombinant HtrA were separated in casein containing gels under non-reducing conditions. Subsequently, gels were renatured in $2.5 \%$ Triton-X-100 and equilibrated in developing buffer [34]. Caseinolytic activity was visualized by staining with $0.5 \%$ Coomassie Blue R250.

\section{Field emission scanning electron microscopy (FESEM)}

Plate-grown $C$. jejuni strains were harvested and fixed in a sterile solution containing $5 \%$ formaldehyde, $2 \%$ 
glutaraldehyde in cacodylate buffer $(0.1 \mathrm{M}$ cacodylate, $0.01 \mathrm{M} \mathrm{CaCl}_{2}, 0.01 \mathrm{M} \mathrm{MgCl}_{2}, 0.09 \mathrm{M}$ sucrose, $\mathrm{pH}$ 6.9) for 1 hour on ice. The solution was centrifuged and passed through a sterile filter. After several washes with cacodylate buffer and TE buffer (20 mM Tris, 1 mM EDTA, pH 6.9), samples were dehydrated in serial dilutions of acetone (10, 30, 50, 70, 90 and 100\%) on ice for 15 min each step. Samples were then allowed to reach room temperature before another change of $100 \%$ acetone, after which they were subjected to critical-point drying with liquid $\mathrm{CO}_{2}$ (CPD030, Bal-Tec). Samples were finally covered with ca. 10.0-nm 11 thick gold film by sputter coating (SCD500, Bal-Tec) and examined in a field emission scanning electron microscope (Zeiss DSM 982 Gemini) using an Everhart Thornley SE detector and in-lens detector in a 50:50 ratio at an acceleration voltage of $5.0 \mathrm{kV}$.

\section{Electron microscopic analysis by negative staining}

For negative staining, thin carbon support films were prepared by indirect sublimation of carbon on freshly cleaved mica. Samples were then absorbed to the carbon film and negatively stained with $1 \%$ (wt/vol) aqueous uranyl acetate $(\mathrm{pH} 4.5)$. After air drying, samples were examined by transmission electron microscopy (TEM) in a Zeiss TEM 910 at an acceleration voltage of $80 \mathrm{kV}$.

\section{Statistical analysis}

All data were evaluated using Student $t$-test with SigmaStat statistical software (version 2.0). Statistical significance was defined by $P \leq 0.05\left(^{*}\right)$ and $P \leq 0.005(* *)$. All error bars shown in figures and those quoted following the $+/-$ signs represent standard deviations.

\section{Additional file}

Additional file 1: Figure S1. Structural and sequence comparison of C. jejuni and H. pylori HtrA proteins. (A) Schematic diagram of the domain arrangement of HtrAs from C. jejuni (Cl) and H. pylori (Hp). (B) Multiple sequence alignment of $H$ trA from different $C$. jejuni and $H$. pylori strains. The protein sequences of Cj 81-176, Cj RM1221, Cj NCTC11168, Hp 26695, Hp P12 and $\mathrm{Hp} 35 \mathrm{~A}$ are aligned. The conserved amino acids of the catalytic triad are indicated in red and shaded with yellow (H: Histidine; D: Aspartic acid; S: Serine). Figure S2. Analysis of wild-type $C$. jejuni and $h$ trA mutants by negative staining and electron microscopy. Investigation revealed that wild-type (Wt) C. jejuni and different htrA mutants of strain 81-176 and NCTC11168 produce intact bipolar flagella (blue arrows) and only slight morphological differences, thus confirming results from FESEM (Figure 1). Each bar corresponds to $1 \mu \mathrm{m}$. Figure S3. Overexpression and purification of C. jejuni HtrA. C. jejuni HtrA was expressed as GST-tag fusion in E. coli BL-21, and then purified as described in Materials and Methods. A Coomassie-stained gel of different fractions and purified HtrA proteins during the purification procedure is shown. Figure S4. Recombinant $C$. jejuni HtrA cleaves E-cadherin but not fibronectin at $42^{\circ} \mathrm{C}$. The experiments were performed under identical conditions as shown in Figure $4 D / E$, but were incubated not incubated at $37^{\circ} \mathrm{C}$ but $42^{\circ} \mathrm{C}$. (A) In vitro cleavage of the recombinant E-cadherin NTF domain performed with purified $C j$ $\mathrm{HtrA}$ or $\mathrm{Hp} \mathrm{HtrA}$ results in several indicated subfragments. (B) In vitro cleavage assay of fibronectin incubated with purified HtrAs under identical conditions shows that fibronectin can be cleaved by $\mathrm{Hp} \mathrm{HtrA}$, but not $\mathrm{Cj} \mathrm{HtrA}$. All reactions were incubated for $16 \mathrm{~h}$.

\section{Competing interests}

The authors declare that they have no competing interests.

\section{Acknowledgements}

We thank Ina Schleicher (HZI Braunschweig, Germany), Dr. Sabine Brandt (University Magdeburg, Germany) and Dr. Marguerite Clyne (UCD Dublin, Ireland) for technical support. We also thank Drs. Patricia Guerry (Fayetteville State University, USA), Michael Konkel (Pullman University, USA), Michael Hensel (University Osnabrueck, Germany), Thomas Meyer (Max Planck Institute for Infection Biology Berlin, Germany) and Juergen Wehland ( $\mathrm{HZI}$ Braunschweig, Germany) for providing the indicated pathogens. The work of S.B. is supported through a SFI grant (UCD 09/IN.1/B2609).

\section{Author details}

${ }^{1}$ From the School for Medicine and Medical Science, University College Dublin, Belfield Campus, Dublin-4, Ireland. ${ }^{2}$ The Division of Microbiology, University Salzburg, A-5020, Salzburg, Austria. ${ }^{3}$ The Department of Medical Microbiology, Helmholtz Center for Infection Research, Inhoffen Str. 7 D38124, Braunschweig, Germany. ${ }^{4}$ The Department of Veterinary Disease Biology, University Copenhagen, Stigbøjlen 4 DK-1870, Frederiksberg C, Denmark. ${ }^{5}$ Institute for Environmental Health, Inc., 15300 Bothell Way NE Lake Forest Park, Seattle, WA 98155, USA. 'Eniversity College Dublin, UCD School of Biomolecular and Biomedical Sciences, Science Center West L231, Belfield Campus, Dublin 4, Ireland.

\section{Authors' contributions}

$M B, B H, M R$ and $N T$ performed and designed the experiments. KTB, LB, OAO and SW provided crucial materials and advise for the experiments. SB, the senior/corresponding author, supervised the experiments and wrote the manuscript together with SW. All authors read and approved the final manuscript.

Received: 6 April 2012 Accepted: 25 April 2012

Published: 25 April 2012

\section{References}

1. World Health Organization: Global burden of disease (GBD) 2002 estimates. WHO 2004. Geneva, Switzerland. [http://www.who.int/topics/ global_burden_of_disease/en/]

2. Young KT, Davis LM, DiRita VJ: Campylobacter jejuni: molecular biology and pathogenesis. Nat Rev Microbiol 2007, 5:665-679.

3. Nachamkin I: Szymanski CM, Blaser MJ: Campylobacter. Washington, DC: ASM Press; 2008

4. Oyarzabal OA, Backert S: Microbial Food Safety: An Introduction. Heidelberg (Germany): Springer Verlag, 2011.

5. Blaser MJ, Engberg J: Clinical aspects of Campylobacter jejuni and Campylobacter coli infections. In Campylobacter. 3rd edition. Edited by Nachamkin I, Szymanski CM, Blaser MJ. Washington, DC: ASM Press; 2008:99-121.

6. Ketley JM: Pathogenesis of enteric infection by Campylobacter. Microbiology 1997, 143:5-21.

7. Wooldridge KG, Ketley JM: Campylobacter-host cell interactions. Trends Microbiol 1997, 5:96-102.

8. Dasti Jl, Tareen AM, Lugert R, Zautner AE, Gross U: Campylobacter jejuni: a brief overview on pathogenicity-associated factors and diseasemediating mechanisms. Int J Med Microbiol 2010, 300:205-211.

9. van Spreeuwel JP, Duursma GC, Meijer CJ, Bax R, Rosekrans PC, Lindeman J: Campylobacter colitis: histological immunohistochemical and ultrastructural findings. Gut 1985, 26:945-951.

10. Oelschlaeger TA, Guerry P, Kopecko DJ: Unusual microtubule-dependent endocytosis mechanisms triggered by Campylobacter jejuni and Citrobacter freundii. Proc Natl Acad Sci USA 1993, 90:6884-6888.

11. Wooldridge KG, Williams PH, Ketley JM: Host signal transduction and endocytosis of Campylobacter jejuni. Microb Pathog 1997, 21:299-305.

12. Pei Z, Burucoa C, Grignon B, Baqar S, Huang XZ, Kopecko DJ, Bourgeois AL, Fauchere $J$, Blaser MJ: Mutation in the peb1A locus of Campylobacter jejuni reduces interactions with epithelial cells and intestinal colonization of mice. Infect Immun 1998, 66:938-943.

13. Konkel ME, Monteville MR, Rivera-Amill V, Joens LA: The pathogenesis of Campylobacter jejuni-mediated enteritis. Curr Issues Intest Microbiol 2001, 2:55-71. 
14. Poly F, Guerry P: Pathogenesis of Campylobacter. Curr Opin Gastroenterol 2008, 24:27-31.

15. Euker TP, Konkel ME: The cooperative action of bacterial fibronectin-binding proteins and secreted proteins promote maximal Campylobacter jejuni invasion of host cells by stimulating membrane ruffling. Cell Microbiol 2012, 14:226-238.

16. Moser I, Schroeder W, Salnikow J: Campylobacter jejuni major outer membrane protein and a 59-kDa protein are involved in binding to fibronectin and INT 407 cell membranes. FEMS Microbiol Lett 1997, 157:233-238.

17. Konkel ME, Gray SA, Kim BJ, Garvis SG, Yoon JJ: Identification of the enteropathogens Campylobacter jejuni and Campylobacter coli based on the cadF virulence gene and its product. Clin Microbiol 1999, 37:510-517.

18. Monteville MR, Yoon JE, Konkel ME: Maximal adherence and invasion of INT 407 cells by Campylobacter jejuni requires the CadF outer-membrane protein and microfilament reorganization. Microbiology 2003, 149:153-165.

19. Krause-Gruszczynska M, Rohde M, Hartig R, Genth H, Schmidt G, Keo T, Koenig W, Miller WG, Konkel ME, Backert S: Role of small Rho GTPases Rac1 and Cdc42 in host cell invasion of Campylobacter jejuni. Cell Microbiol 2007, 9:2431-2444.

20. Krause-Gruszczynska M, Boehm M, Rohde M, Tegtmeyer N, Takahashi S, Buday L, Oyarzabal OA, Backert S: The signaling pathway of Campylobacter jejuni-induced Cdc42 activation: Role of fibronectin, integrin beta1, tyrosine kinases and guanine exchange factor Vav2. Cell Commun Signal 2011, 9:32.

21. Boehm M, Krause-Gruszczynska M, Rohde M, Tegtmeyer N, Takahashi S, Oyarzabal OA, Backert S: Major host factors involved in epithelial cell invasion of Campylobacter jejuni: Role of fibronectin, integrin beta1, FAK, Tiam-1 and DOCK180 in activating Rho GTPase Rac1. Front Cell Infect Microbiol, 2011, 1: DOl=10.3389/fcimb.2011.00017.

22. Kazmierczak BI, Mostov K, Engel JN: Interaction of bacterial pathogens with polarized epithelium. Annu Rev Microbiol 2001, 55:407-435.

23. Tegtmeyer N, Rohde M, Backert S: Clinical presentations and pathogenicity mechanisms of bacterial foodborne diseases. In Microbial Food Safety: An Introduction. Oyarzabal OA, Backert S (eds.). Heidelberg (Germany): Springer, 2011:13-31.

24. Balkovetz DF, Katz J: Bacterial invasion by a paracellular route: divide and conquer. Microbes Infect 2003, 5:613-619.

25. Konkel ME, Mead DJ, Hayes SF, Cieplak W Jr: Translocation of Campylobacter jejuni across human polarized epithelial cell monolayer cultures. J Infect Dis 1992, 166:308-315.

26. Grant CCR, Konkel ME, Cieplak W Jr, Tompkins LS: Role of flagella in adherence, internalization, and translocation of Campylobacter jejuni in nonpolarized and polarized epithelial cell cultures. Infect Immun 1993, 61:1764-1771.

27. Van Deun K, Pasmans F, Van Immerseel F, Ducatelle R, Haesebrouck F: Butyrate protects Caco-2 cells from Campylobacter jejuni invasion and translocation. Br J Nutr 2008, 100:480-484.

28. Monteville MR, Konkel ME: Fibronectin-facilitated invasion of T84 eukaryotic cells by Campylobacter jejuni occurs preferentially at the basolateral cell surface. Infect Immun 2002, 70:6665-6671.

29. Hu L, Tall BD, Curtis SK, Kopecko DJ: Enhanced microscopic definition of Campylobacter jejuni 81-176 adherence to, invasion of, translocation across, and exocytosis from polarized human intestinal Caco-2 cells. Infect Immun 2008, 76:5294-5304.

30. Kalischuk LD, Inglis GD, Buret AG: Campylobacter jejuni induces transcellular translocation of commensal bacteria via lipid rafts. Gut Pathog 2009, 1:2.

31. Ó Cróinín T, Backert S: Host epithelial cell invasion by Campylobacter jejuni: trigger or zipper mechanism? Front. Cell. Inf Microbio. 2:25 doi: 10.3389/fcimb.2012.00025

32. Hoy B, Löwer M, Weydig C, Carra G, Tegtmeyer N, Geppert T, Schröder P, Sewald N, Backert S, Schneider G, Wessler S: Helicobacter pylori HtrA is a new secreted virulence factor that cleaves E-cadherin to disrupt intercellular adhesion. EMBO Rep 2010, 11:798-804.

33. Hoy B, Geppert T, Boehm M, Reisen F, Plattner P, Gadermaier G, Sewald N, Ferreira F, Briza P, Schneider G, Backert S, Wessler S: Distinct roles of secreted HtrA proteases from Gram-negative pathogens in cleaving the junctional protein and tumor suppressor E-cadherin. J Biol Chem 2012, 287:10115-10120.

34. Löwer M, Weydig C, Metzler D, Reuter A, Starzinski-Powitz A, Wessler S, Schneider G: Prediction of extracellular proteases of the human pathogen Helicobacter pylori reveals proteolytic activity of the Hp1018/19 protein HtrA. Plos One $2008,3 \cdot e 3510$.
35. Brøndsted L, Andersen MT, Parker M, Jørgensen $K$, Ingmer $H$ : The HtrA protease of Campylobacter jejuni is required for heat and oxygen tolerance and for optimal interaction with human epithelial cells. Appl Environ Microbiol 2005, 71:3205-3212.

36. Bæk KT, Vegge CS, Brøndsted L: HtrA chaperone activity contributes to host cell binding in Campylobacter jejuni. Gut Pathog 2011, 3:13.

37. Baek KT, Vegge CS, Skórko-Glonek J, Brøndsted L: Different contributions of HtrA protease and chaperone activities to Campylobacter jejuni stress tolerance and physiology. Appl Environ Microbiol 2011, 77:57-66.

38. Krojer T, Sawa J, Schäfer E, Saibil HR, Ehrmann M, Clausen T: Structural basis for the regulated protease and chaperone function of DegP. Nature 2008, 453:885-890.

39. Kim DY, Kim KK: Structure and function of HtrA family proteins, the key players in protein quality control. J Biochem Mol Biol 2005, 38:266-274.

40. Clausen T, Southan C, Ehrmann M: The HtrA family of proteases: implications for protein composition and cell fate. Mol Cell 2002, 10:443-455.

41. Bumann D, Aksu S, Wendland M, Janek K, Zimny-Arndt U, Sabarth N, Meyer TF, Jungblut PR: Proteome analysis of secreted proteins of the gastric pathogen Helicobacter pylori. Infect Immun 2002, 70:3396-3403.

42. Wroblewski LE, Shen L, Ogden S, Romero-Gallo J, Lapierre LA, Israel DA, Turner JR, Peek RM Jr: Helicobacter pylori dysregulation of gastric epithelial tight junctions by urease-mediated myosin II activation. Gastroenterology 2009, 136:236-246

43. Cossart P, Sansonetti PJ: Bacterial invasion: the paradigms of enteroinvasive pathogens. Science 2004, 304:242-248.

44. Rottner K, Stradal TE, Wehland J: Bacteria-host-cell interactions at the plasma membrane: stories on actin cytoskeleton subversion. Dev Cell 2005, 9:3-17.

45. Backert S, König W: Interplay of bacterial toxins with host defense: molecular mechanisms of immunomodulatory signaling. Int J Med Microbiol 2005, 295:519-530.

46. Gerlach RG, Hensel M: Salmonella pathogenicity islands in host specificity, host pathogen-interactions and antibiotics resistance of Salmonella enterica. Berl Munch Tierarztl Wochenschr 2007, 120:317-327.

47. Stecher B, Hardt WD: The role of microbiota in infectious disease. Trends Microbiol 2008, 16:107-114

48. Tsolis RM, Young GM, Solnick JV, Bäumler AJ: From bench to bedside: stealth of enteroinvasive pathogens. Nat Rev Microbiol 2008, 6:883-892.

49. Everest PH, Goossens H, Butzler JP, Lloyd D, Knutton S, Ketley JM, Williams $\mathrm{PH}$ : Differentiated Caco-2 cells as a model for enteric invasion by Campylobacter jejuni and C. coli. J Med Microbiol 1992, 37:319-325.

50. Harvey P, Battle T, Leach S: Different invasion phenotypes of Campylobacter isolates in Caco-2 cell monolayers. J Med Microbiol 1999, 48:461-469.

51. Brás AM, Ketley JM: Transcellular translocation of Campylobacter jejuni across human polarised epithelial monolayers. FEMS Microbiol Lett 1999, 179:209-215.

52. Chen ML, Ge Z, Fox JG, Schauer DB: Disruption of tight junctions and induction of proinflammatory cytokine responses in colonic epithelial cells by Campylobacter jejuni. Infect Immun 2006, 74:6581-6589.

53. Wine E, Chan VL, Sherman PM: Campylobacter jejuni mediated disruption of polarized epithelial monolayers is cell-type specific, time dependent, and correlates with bacterial invasion. Pediatr Res 2008, 64:599-604

54. Pogacar MS, Klancnik A, Mozina SS, Cencic A: Attachment, invasion, and translocation of Campylobacter jejuni in pig small-intestinal epithelial cells. Foodborne Pathog Dis 2010, 7:589-595.

55. Biswas D, Niwa H, Itoh K: Infection with Campylobacter jejuni induces tyrosine-phosphorylated proteins into INT-407 cells. Microbiol Immuno $2004,48: 221-228$.

56. Hu L, McDaniel JP, Kopecko DJ: Signal transduction events involved in human epithelial cell invasion by Campylobacter jejuni 81-176. Microb Pathog 2006, 40:91-100.

57. Konkel ME, Garvis SD, Tipton S, Anderson DE, Cieplak W Jr: Identification and molecular cloning of a gene encoding a fibronectin binding protein (CadF) from Campylobacter jejuni. Mol Microbiol 1997, 24:953-963.

58. Goon S, Ewing CP, Lorenzo M, Pattarini D, Majam G, Guerry P: $\sigma^{28}$-regulated nonflagella gene contributes to virulence of Campylobacter jejuni 81-176. Infect Immun 2006, 74:769-772.

doi:10.1186/1757-4749-4-3

Cite this article as: Boehm et al:: Rapid paracellular transmigration of Campylobacter jejuni across polarized epithelial cells without affecting TER: role of proteolytic-active HtrA cleaving E-cadherin but not fibronectin. Gut Pathogens 2012 4:3. 